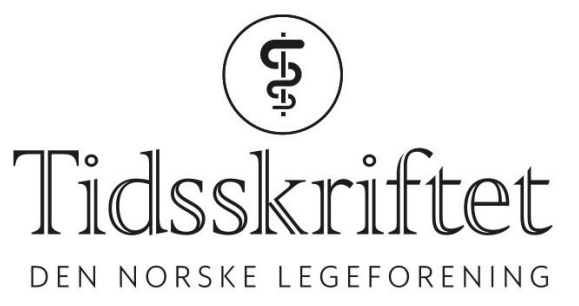

\title{
Barnelegen for de minste
}

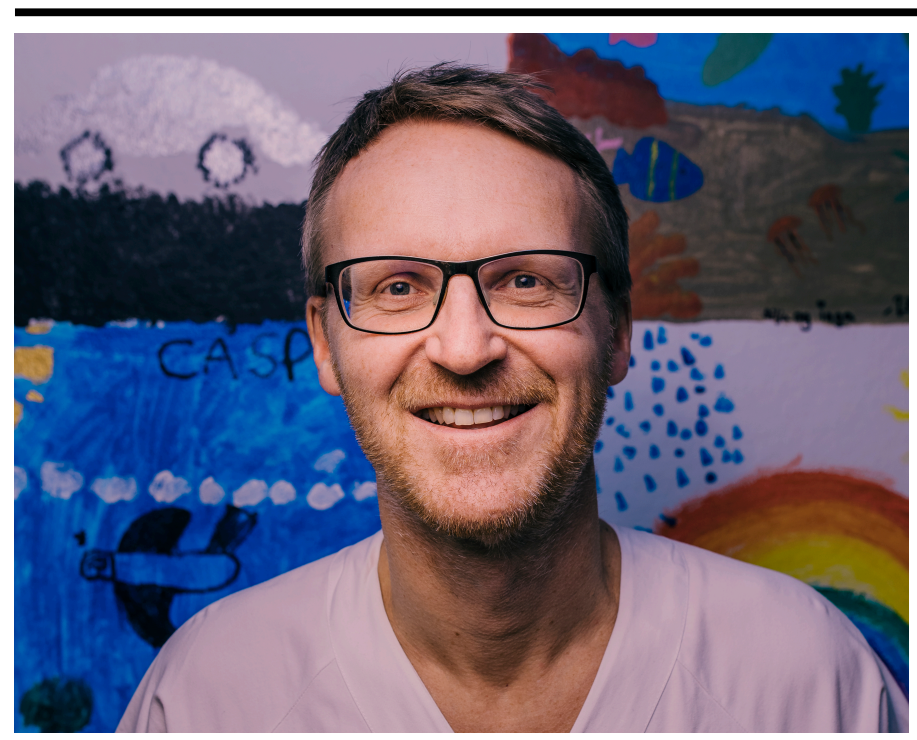

INTERVJU

RUNE SKOGHEIM

E-post: runeskogheim@hotmail.com

Claus Klingenberg både redder premature nordboere og hamrer faglige veiledere frem på tastaturet i en fandens fart. Men egentlig er han en simpel epletjuv. 


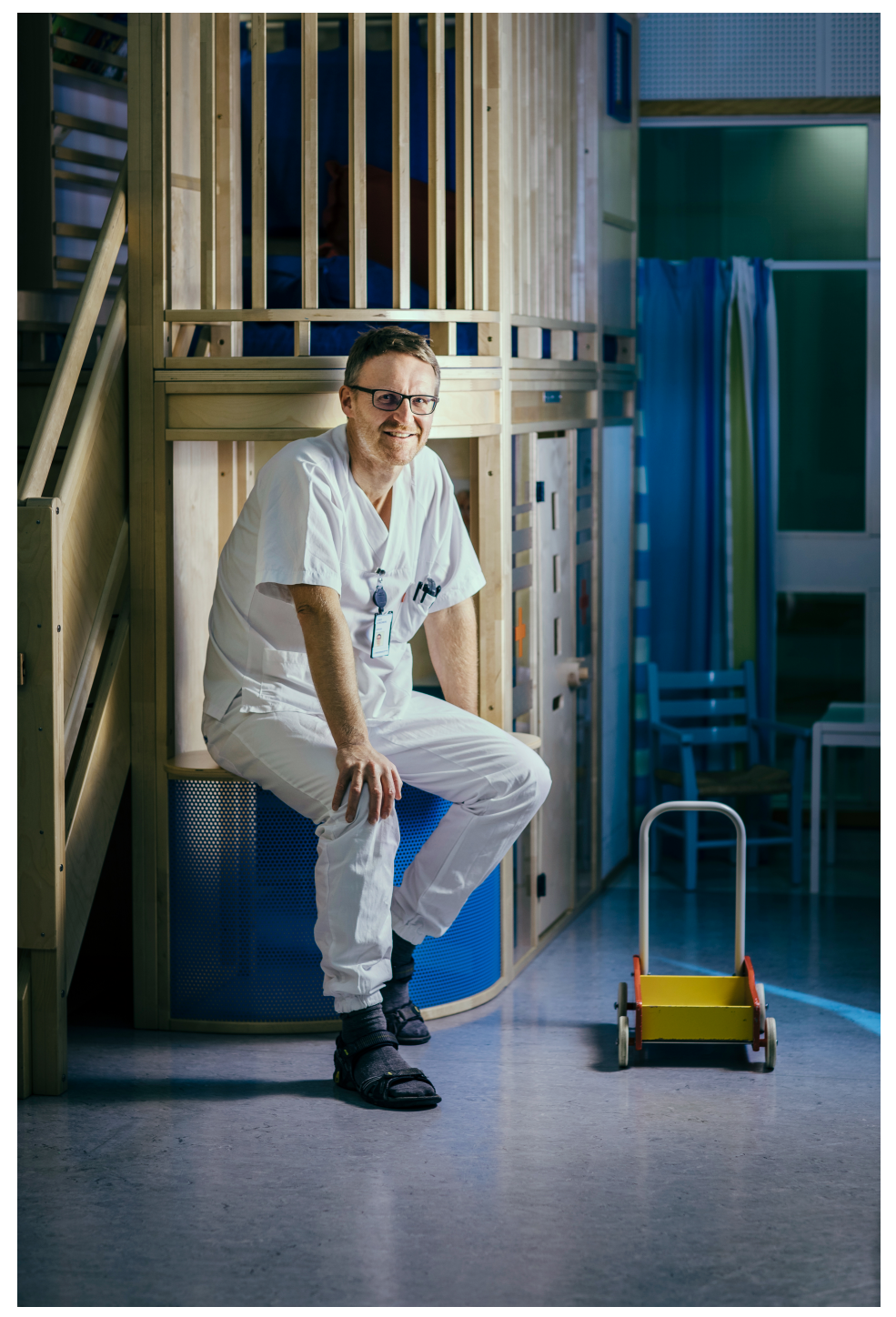

Det er en solrik ettermiddag i Asker i midten av 1970-årene. Den plystrende syvåringen Claus Klingenberg rusler hjemover fra skolen med ranselen på ryggen. Han sparker noen småstein i grøfta, hopper over et kumlokk og løfter plutselig blikket mot en spennende silhuett på himmelen. Claus legger hodet bakover, skygger med hånden og myser opp på et glinsende rødt og deilig eple. Han kikker seg tilforlatelig over skulderen og smetter raskt opp gjerdet som grenen strekker seg over. Piggtråd. Pulsøkning. Kroppen er liten og lett, men grenene blir gradvis tynnere og han skjønner skjebnen rett før han legger vekten på den siste kvisten. Pupillene vider seg ut, det røde eplet brennes fast på netthinnen og han blir vektløs.

- Så deiset jeg bare rett ned på piggtrådgjerdet. Det gjorde jo selvsagt fryktelig vondt. Jeg hadde skrapet meg opp ganske så bra altså, sjekk her!

Klingenberg drar opp ermet på sykehustrøya og leter etter minnene fra syndefallet. Han er merket for livet: Det ses to hvite arr på 2 x 2 centimeter medialt på høyre overarm. Den nå så erfarne barnelegen har ikke glemt møtet med legevaktlegen i Oslo, da han selv var en liten og redd pasient.

\section{Den viktigste bilen i barneland}

- Jeg husker at jeg var innmari nervøs på venterommet og lurte på hva jeg skulle si til legen når han spurte hva som hadde skjedd, for jeg skammet meg sånn. Men han lurte det liksom ut av meg med en gang, og da holdt han bare på å le seg i hjel. Så ga han meg masse tips om hvor jeg kunne gå trygt på epleslang i området jeg bodde. Jeg ble så lettet og syntes han var kjempemorsom. Han ga meg stivkrampesprøyte, lokalbedøvelse og sydde kuttene, men fjaset og tullet med meg hele tiden slik at jeg nesten ikke husket hva som hadde skjedd 


\section{Claus Klingenberg}

Født 1967

Medisinstudium Ulm, Tyskland 1986-1992

Assistentlege, Barne- og ungdomsavdelingen, Universitetssykehuset Nord-Norge, fra 1995

Barneavdelingen, Kilimanjaro Christian Medical Center, Tanzania 1998/99 (6 måneder)

Overlege, Barne- og ungdomsavdelingen, Universitetssykehuset Nord-Norge 1999

Spesialist i barnesykdommer 2001

Dr.med, Universitetet i Tromsø, på et prosjekt om infeksjoner hos nyfødte, 2006

Forskningsopphold på nyfødtavdeling i Melbourne, Australia 2009-10

Professor ved Universitetet i Tromsø og seksjonsoverlege på Nyfødt intensiv,

Universitetssykehuset Nord-Norge fra 2013

Redaktør av Norsk barnelegeforenings veiledere i pediatri

- Hvordan er du selv i møtet med barn som pasienter?

- Starten er veldig viktig. Trikset er å prøve å få en slags kontakt før man skal undersøke dem, men hva som fungerer er veldig aldersavhengig. Jeg hadde for eksempel en åtteåring på poliklinikken som hadde litt problemer med at han tisset på seg om natten, og det forsto jeg kanskje ikke var så kult for han å fortelle om. Da kan man begynne med noe helt annet. Jeg hadde skjønt at han var litt av en spreking, så han fikk vise meg noen triks og slo hjul bortover gangen før han gikk på hendene inn på kontoret. Det var veldig gøy for begge to, og så var isen brutt. Nevrologisk undersøkelse var for så vidt også bestått.

Det er ikke så vanskelig å se for seg at mannen i sofaen kan sjarmere de små. Han virker trygg og naturlig når han lener seg tilbake, men ivrig og oppmerksom når han bøyer seg frem. Han smiler stadig, ler hjertelig, og jeg har selv bevitnet at han er en racer på tegnefilmreferanser.

- Jeg husker du var veileder da jeg skulle undersøke en liten gutt på gruppeundervisning i pediatri, og jeg var ganske fornøyd med å kommentere at han hadde motiv fra «Cars» på genseren. Men du kunne briljere mer enn som så?

- Jajaja, det var jo «McQueen» jo, «Lynet McQueen»! Sånne ting må du følge med på, vet du. Han har faktisk holdt seg godt over tid, sånn som kaptein Sabeltann. Og julenissen da, i sesongen kan man jo alltid spørre barna hva han sier, så kan de svare «Ho, ho, ho!» og synes alt er helt topp.

\section{Skyld og solskinn}

Utenfor sykehuset ligger mørket tettpakket inntil veggene og mellom vinduene. Parklyset fra en taxi lyser opp strømmende regndråper som bygger et nytt lag med issvuller over den siste strøgrusen. Claus Klingenberg har forlenget enda en arbeidsdag med enda et møte. Men seksjonsoverlegen på barneavdelingen på Universitetssykehuset Nord-Norge i Troms $\emptyset$ synes ikke synd på seg selv, det er mange her inne som ønsker seg hjem.

- De her møtene... det er bare så mange av dem at jeg blir helt matt iblant. Men det er en nødvendig del av jobben min. Dersom man vil være med å påvirke beslutninger, kan man ikke la være å delta på møter. Da har du ikke noe du skulle ha sagt hvis du ikke liker utviklingen, sier Klingenberg bestemt.

- Du har kanskje hatt tøffere dager på jobben?

- Ja, det hender jo det er tunge situasjoner hvor det ikke går så bra med barna som man skulle ønske... 
- Hvordan da?

- Det kan for eksempel være nyfødte med komplikasjoner hvor man tror man har klart å komme over en kneik, og så kommer det nye nedturer, selv om man prøver å gjøre sitt aller beste. Det er selvfølgelig verst for foreldrene som opplever alle disse opp- og nedturene, men som lege er det også belastende. Det kan gnage på deg.

- Får du skyldfølelse?

- Ja, det gjør jeg. Når for tidlig fødte barn blir veldig syke, lurer du i blant på om det var din feil at det ble sånn eller om det hadde skjedd uansett fordi de er så skjøre. Men vi er jo et team og en avdeling som organiserer behandlingen, så det er sjelden noe er én person sin skyld. Man ønsker bare så sterkt at ting skulle gått bedre for dem.

Heldigvis er det mange blide barnefjes og takknemlige foreldre som oppveier for de tunge stundene for en sliter i hvitt. Klingenberg får også oppleve at små kropper som ble holdt $\mathrm{i}$ live av medisiner og maskiner noen år senere spretter fornøyde inn på kontoret hans med en tegning. Han har fått klemmer og julekort, og for litt siden kunne han vinke smilende til en jente han har fulgt i flere år da hun sto på scenen i en hovedrolle på Hålogaland Teater.

\section{Visste ikke engang hvor coilen var}

16.30 er et skummelt tidspunkt for en intervjuavtale. Jeg har lest at dommere godkjenner flest søknader om benådning om morgenen og rett etter lunsj. Etter det daler velviljen i takt med blodsukkeret. Men jeg og Peppe vet råd. Råd med rømmedressing.

Maratonmøtemannen sluker et stykke før vi reiser noen år bakover og noen mil sørover.

- Jeg vokste opp i et byggefelt i Asker med masse innflyttere fra overalt, en fin oppvekst der det meste lenge dreide seg om svømming. Jeg ble veldig tidlig opptatt av å svømme og det var hovedhobbyen min fra jeg var ti til jeg var atten år omtrent, forteller Klingenberg.

Broren hans var tre år eldre og drev med samme idrett, men i svømmehallen holdt lillebror seg på respektfull avstand.

- Sånn var det. Da jeg var ti og han var tretten, turte jeg jo nesten ikke å snakke til han engang. I den alderen der synes jo han at jeg bare var en liten tulling, vet du.

- Hadde han rett?

- Hehe! Nei, det vil jeg ikke si. Men vi har god kontakt nå da, bortsett fra at han bor i Oslo og ikke skjønner hva jeg driver med her oppe i «ødeland».

Da den unge svømmeren var ferdig med videregående, ville han ta et jobbår. Et hyggelig intervju i en barnehage hadde nesten overbevist han om å bli barnehageassistent, men Dikemark psykiatriske sykehus spiste barnehagelønninger til frokost og unge Klingenberg ble pleiemedhjelper. En lang karriere i helsevesenet var i gang.

- Jeg visste at jeg ville ta høyere utdanning og var ikke interessert i økonomi, ikke var jeg ingeniør- eller mekanikertypen heller. Jeg kunne mekke litt på mopeden og skifte noen tennplugger, men visste knapt hvor coilen var. Etter hvert skjønte jeg at legeyrket kunne passe for meg, sier han og slår ut med hendene.

Jeg smiler overbærende til han mens jeg rister lett på hodet, selv om jeg egentlig ikke vet hva coilen er en gang. Senere har jeg fått greie på at coilen i en bensinmotor sørger for å transformere batteriets lave spenning til voltmengden som kreves for å skape en gnist i tennpluggene, som igjen antenner bensinen og starter motoren.

\section{En diplomatisk linedans}

Claus Klingenberg dro så for å studere medisin i Ulm i Tyskland. I starten kunne han iblant føle seg fremmed og fortapt, men etter hvert som han fikk dreisen på språket fikk han snart mange tyske venner.

- Hvordan var det å være student på et tysk sykehus? 
- Det var ekstremt hierarkisk. Man var helt prisgitt overlegenes humør og kunne bli kjeftet huden full dersom man glemte seg og sa «du» istedenfor «De». Jeg husker jeg gikk forbi en professor i gangen mens han sto og snakket med noen, hvorpå han plutselig snudde seg etter meg og utbrøt fornærmet: «Kan du ikke det minste si god dag herr professor når du går forbi meg?!». Noen av dem var nærmest psykopater, sier han, som selv har blitt en atskillig lunere professor, mens han rister på hodet. Den unge nordmannen følte det som befriende å jobbe hjemme på Bærum sykehus i feriene.

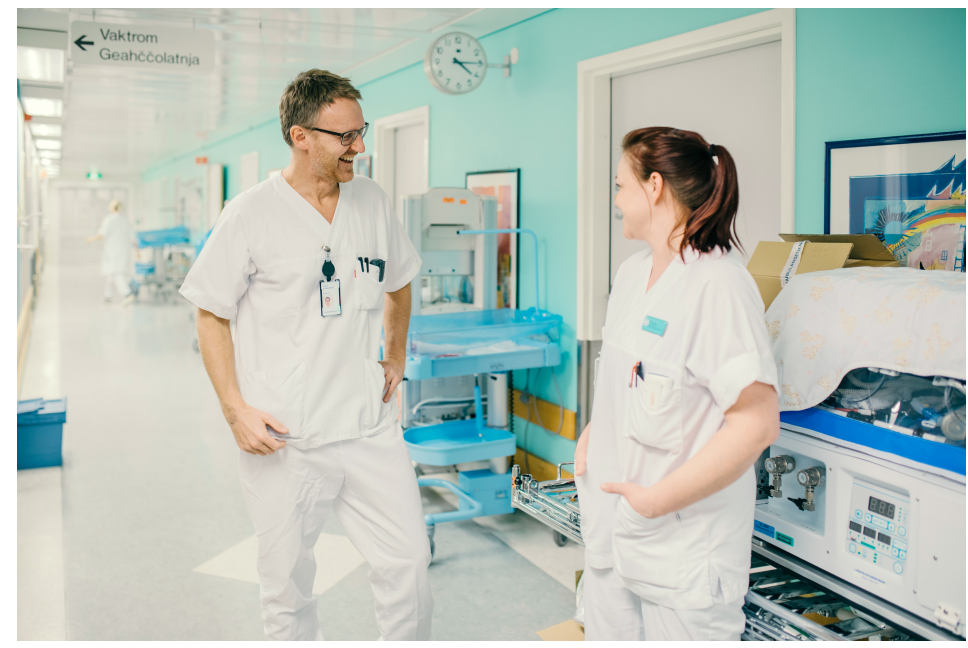

Da han skulle avtjene verneplikten, ønsket han seg til helikoptertjeneste på Ørlandet. Der fikk han den tvilsomme gleden av å være første militærlege som måtte bli igjen på bakken og gjøre helsesjekker mens anestesilegene hoppet i flydressen, kastet på luggen og steg glisende om bord. Men baksetetur i F-16, det fikk han med seg.

- Det var innmari kult, og jeg spydde ikke engang! Piloten jeg var med opp, hadde kræsjet et F-16-fly tidligere, så jeg regnet det som statistisk veldig lite sannsynlig at han ville gjøre det to ganger, forklarer Klingenberg.

Jeg stusser litt over seksjonsoverlegens sannsynlighetsberegninger, men konstaterer at han likevel har klart seg godt. I 20 år har han vært en del av kuvøseteamet som flyr ut for å hjelpe de sykeste av Nord-Norges nye borgere, i tillegg til å undervise på lokalsykehusene. Han har vært sentral i arbeidet med Barnelegeforeningens faglige veiledere, de siste årene som redaktør, og har selv skrevet mye av tromsømiljøets populære metodebok for nyfødtmedisin.

- Å være redaktør kan være en diplomatisk linedans, for jeg er litt utålmodig, men kan heller ikke mase for mye på bidragsyterne som gjør en frivillig og flott innsats. Da er det lettere med metodeboken der jeg bare kan gjøre jobben selv, sier han kjapt og prøver å rekke et nytt pizzastykke før han blir stilt til svars igjen.

\section{«Kamelåså»?}

- Du sier du er en utålmodig type, hvordan er det å jobbe med barn da?

- Jeg tror jeg klarer å tøyle meg ganske greit altså, jeg er kanskje mer tålmodig med barn enn med voksne. Barn har ikke så ekstremt mye tålmodighet selv da, de er litt mer «i nuet». Sånn sett passer vi egentlig godt sammen. Man kan ikke være langsom med barn, men noen foreldre synes sikkert jeg er for travel iblant.

- Vi snakker ofte om å være «flink med barn», men hvordan er man «flink med foreldre»?

- For det første må du kunne faget ditt godt, du må ha greie på hva du snakker om. Også må du ha forberedt deg, lest i journalen og vise at du lytter og tar dem på alvor. Men foreldrene er like forskjellige som barna, så man kan ikke behandle alle dem likt heller, sier Klingenberg.

Selv er han far til en jente på 18 som nettopp har flyttet til Oslo for å satse på svømming, i tillegg til to tvillinger, en gutt og en jente, på 16 år. Er det to ting de har blitt lei av å høre i 
oppveksten, så er det 1) «Det går nok over» og 2) Genesis.

- De har gitt ganske klart uttrykk for at de ikke liker musikken min. Jeg fikk liksom med meg at Coldplay var bra, men har nok stagnert litt når det gjelder å oppdage nye band. Det må være en alderssvakhet eller noe. Jeg kan noen ganger tenke at jeg burde søke opp noe nytt, men så sitter jeg der og har liksom mest lyst til å høre på Neil Young da...

Humormessig har han også sansen for gode årganger og synes Harald Eia og Bård Tufte Johansen på sitt beste var hysterisk morsomme.

- «Den lille gangetabellen», for eksempel, er jo sinnssykt bra. Og den sketsjen der danskene ikke forstår språket sitt lenger og sier sånn «kamelåååså?», hermer professoren.

Så utveksler vi noen klassiske replikker på tulledansk og humrer litt forlegent for oss selv.

\section{Ellevill barnelege banner i sjokkintervju}

Etter at Klingenberg en tankeknakende helg på Ørlandet endte med å velge sommerjobb på barneavdelingen i Tromsø foran medisinsk avdeling på Bærum sykehus, har han slått rot i nord. Men det hender han drømmer seg tilbake til da han kjørte rundt i Land Rover i Tanzania mens han jobbet et halvår uten lønn på en barneavdeling i Moshi, ved foten av Kilimanjaro. Han har også jobbet i Australia på overlegepermisjon. Dit er det langt lettere å få med familien, for eksempel i juleferien som var.

- Det var veldig deilig å slappe av med sol og varme, men familieidretten er jo svømming, så en av dagene var hele gjengen med på et «ocean race» på 1200 meter. Det blir litt som turlangrenn der borte, forteller han ivrig.

- Vant du?

- Nei, er du gæærn?!

- Men innad i familien tenkte jeg på?

- Nei, er du gæærn?! Datteren min trener jo svømming, så hun vant selvfølgelig. Kona mi slo meg faktisk også, men jeg har så dårlig retningssans og svømmer så mye sikksakk at jeg hadde sikkert svømt dobbelt så langt som de andre, forsvarer han seg.

Sikksakksvømmeren har til og med prøvd seg som speaker på svømmestevner og kunne gjerne tenkt seg en reservekarriere som sportskommentator. Men journalistikk for øvrig har han utviklet et lunkent forhold til.

- Da jeg nevnte at jeg hadde journalistutdanning, husker jeg at du sa «jasså, du er en av fienden?» Hvorfor sa du det?

- Det var jo litt på gøy da, men jeg har noen negative erfaringer med mediene og har opplevd situasjoner som virkelig har blitt feilaktig fremstilt. Vi må selvfølgelig samarbeide med journalister, men når jeg ser hvor mye feil som gjøres på mitt fagområde, tenker jeg at da er det vel sånn på andre fagområder også. Vanskelige ting blir ofte forenklet og sensasjonspreget.

- Er du redd for at dette intervjuet med deg også skal bli for sensasjonspreget?

- Haha! Nei, for når jeg får det til gjennomlesing, kommer jeg til å sensurere det noe jævlig!

Publisert: 28. mai 2018. Tidsskr Nor Legeforen. DOI:10.4045/tidsskr.18.0161

(C) Tidsskrift for Den norske legeforening 2020. Lastet ned fra tidsskriftet.no 